\title{
The allelic distribution of -308 Tumor Necrosis Factor-alpha gene polymorphism in South African women with cervical cancer and control women
}

\author{
Vandana A Govan*1, Debbie Constant ${ }^{2}$, Margaret Hoffman ${ }^{2}$ and Anna- \\ Lise Williamson ${ }^{1,3}$
}

Address: ${ }^{1}$ Division of Medical Virology, Institute of Infectious Diseases and Molecular Medicine, University of Cape Town, Observatory, Cape Town, South Africa, ${ }^{2}$ School of Public Health, Faculty of Health Sciences, University of Cape Town, Observatory, Cape Town, South Africa and ${ }^{3}$ National Health Laboratory Services, Observatory, Cape Town

Email: Vandana A Govan* - vgovan@curie.uct.ac.za; Debbie Constant - constant@cormack.uct.ac.za; Margaret Hoffman - mh@cormack.uct.ac.za; Anna-Lise Williamson - annalise@curie.uct.ac.za

* Corresponding author

Published: 26 January 2006

BMC Cancer 2006, 6:24 doi:10.1 186/147|-2407-6-24

This article is available from: http://www.biomedcentral.com/I47I-2407/6/24

(c) 2006 Govan et al; licensee BioMed Central Ltd.

This is an Open Access article distributed under the terms of the Creative Commons Attribution License (http://creativecommons.org/licenses/by/2.0), which permits unrestricted use, distribution, and reproduction in any medium, provided the original work is properly cited.
Received: 07 September 2005

Accepted: 26 January 2006

\begin{abstract}
Background: Cervical cancer is due to infection with specific high-risk types of human papillomavirus (HPV). Although the incidence of genital HPV infection in various population groups is high, most of these regress without intervention. Investigating genetic host factors and cellular immune responses, particularly cytokines, could help to understand the association between genital HPV infection and carcinogenesis. The tumor necrosis factor alpha (TNF- $\alpha$ ) cytokine plays an important role in all stages of cervical cancer and has the ability to induce the regression of human tumors. Therefore the aim of the study was to investigate the allelic distribution of -308 TNF- $\alpha$ gene polymorphism in South African women with cervical cancer compared to control women.

Methods: Included in our study were women with histologically proven cancer of the cervix $(n=244)$ and hospital-based controls $(n=228)$. All patients and controls were from mixed race and black population groups in South Africa. The detection of a bi-allelic -308 (A/G) polymorphism in the promoter region of TNF- $\alpha$ was investigated using the amplification refractory mutation system-polymerase chain reaction (ARMS-PCR) technique. The distributions of the allelic frequencies were stratified in both patients and controls into two South African ethnic population groups.

Results: In this study we observed no association between the distribution of -308 TNF- $\alpha$ polymorphism and the risk of developing cervical cancer even after combining the data from the two ethnic populations $\left(X^{2}=2.26\right)$. In addition, using the chi-squared test we found no significant association between the known risk factors for cervical cancer and the allele distribution of -308 TNF- $\alpha$. However, the frequency of the rare high-producing allele -308A of TNF- $\alpha$ was significantly lower in the South African population when compared to Caucasians and Chinese population groups.

Conclusion: We demonstrated no association between -308 TNF- $\alpha$ polymorphism and the risk of cervical cancer among two South African ethnic population groups. However, as the distribution of the 308A TNF- $\alpha$ was notably different between the control groups of South Africa and other population groups this result suggests that ethnic disparity may influence the levels of TNF- $\alpha$ produced.
\end{abstract}




\section{Background}

There is strong epidemiological and experimental data that have demonstrated a definite association of high-risk human papillomavirus (HR-HPV) infection and the development of cervical cancer [1]. Interestingly, although most sexually active women in the normal population have asymptomatic cervical HPV infections, most of these cervical infections are transient, with clearance in $70 \%$ to $90 \%$ of individuals positive for HPV DNA. In addition, only a small percentage develops long-term HPV infection, which is associated with an increased risk of developing cervical cancer [2]. Thus, an effective host immune response may be an important determinant for the persistence and progression of HPV induced cervical cancer. In particular, cell-mediated immunity (CMI) is important in controlling both HPV infections and HPVassociated neoplasms [3]. CMI is regulated by cytokines that are secreted primarily by $\mathrm{T}$ helper (Th) cells and macrophages.

Cytokines play a significant role in the defense against HPV induced infections, modulating viral replication and polarizing the immune response to a Th1 (cellular) or Th2 (humoral) pattern [1]. Th1 cells are immuno-stimulatory and are associated with the clearance of HPV infection and regression of cervical intraepithelial neoplasia [4] Th2 cells are immuno-inhibitory and are capable of stimulating tumor growth [5]. Investigating genetic host factors and immune responses could help to understand the association between genital HPV infection and carcinogenesis [6], as cervical cancer is the second most common female cancer worldwide and the most common cancer in South Africa among women, which continues to be a public health burden. Several candidate gene studies have demonstrated that genetic polymorphisms in cytokine genes contribute to the variation in the levels of cytokine produced and this variation may influence the severity of several infectious diseases [7-9]. Among them the proinflammatory cytokine, tumor necrosis factor-alpha (TNF- $\alpha$ ) has been of particular interest as it was found to be located in the central major histocompatibility complex (MHC) and a possible genetic correlation between TNF alleles and disease susceptibility was hypothesized [10].

TNF- $\alpha$ is a multifunctional cytokine that was originally identified as a macrophage-derived serum protein that mediates necrosis of solid tumors in vitro and in vivo [11]. In addition, TNF has been shown to mediate carcinogenesis through induction of proliferation, invasion, and metastasis of tumor cells [12]. Furthermore, it was shown that the expression of TNF- $\alpha$ is regulated at the transcriptional level [13] and various polymorphisms within the TNF- $\alpha$ promoter region have been associated with the level of TNF- $\alpha$ produced $[10,14,15]$. Several investigators have studied the polymorphisms within the TNF- $\alpha$ promoter region to estimate the immune responses to a wide range of cancers $[9,16,17]$ including cervical cancer $[18,19]$. In particular, the biallelic polymorphism in the promoter region at position -308 relative to the transcriptional start site of the gene, representing a transition from the nucleotides guanine $(\mathrm{G})$ to adenine $(\mathrm{A})$ has been commonly studied. This $-308 \mathrm{G} / \mathrm{A}$ transition affects the expression of TNF- $\alpha$ where the less common -308A allele produces higher levels of TNF- $\alpha$, while the $-308 \mathrm{G}$ allele is linked to a reduced TNF- $\alpha$ production $[10,20]$. Indeed, these observations presented the possibility that tumor development may be associated to the genetic predisposition of the host to produce higher levels of TNF- $\alpha$. Numerous studies have investigated the association between the effect of TNF- $\alpha$ promoter region and cervical cancer, but the results have been contradictory $[9,18,21,22]$. Notably, these findings are from different population groups and thus indicate that the variation in TNF- $\alpha$ production may be influenced by the genetic make-up of diverse population groups contributing to a disparity in disease outcome.

Therefore, given the importance of TNF- $\alpha$ in potentially contributing to the progression of cervical cancer with variations in the levels of TNF production in different population groups, we investigated the biallelic polymorphism in the -308 promoter region of the TNF- $\alpha$ gene using the ARMS-PCR methodology and examined its relationship to the development of cervical cancer among two South African ethnic groups.

\section{Methods \\ Patients and control populations}

Individuals were selected from a case-control study of cancer of the cervix and related risk factors conducted among colored (mixed racial descent) and black women residing in the Western Cape Province of South Africa, from January 1998 to December 2001 [23]. The Research Ethics Committee, Faculty of Health Sciences, University of Cape Town, South Africa, approved the case-control study. Cases were women with invasive cancer of the cervix attending Gynae-oncology clinics at 2 tertiary hospitals. The controls, who were hospital based, were women with primary diagnosis such as trauma or acute infections that were judged to be independent of contraceptive use and had no history or evidence of cervical disease and were identified at the 2 tertiary hospitals. The controls were series matched to cases for decade age, ethnic group and area of residence. Data on known risk factors and potential confounders were collected using a detailed questionnaire administered by trained nurse interviewers. Papanicoloau (Pap) smears were taken from all control women. Blood samples from randomly selected 244 eligible cervical cancer patients and 228 hospital-based con- 
Table I: Odds Ratios and $95 \%$ confidence intervals $(\mathrm{Cl})$ for the development of cervical cancer in relation to -308 TNF- $\alpha$ alleles among the cervical cancer cases and controls in the two South African ethnic population groups.

\begin{tabular}{|c|c|c|c|c|}
\hline Race & Genotype & CaCx n (\%) & Controls n (\%) & $\mathrm{OR}^{\prime}(95 \% \mathrm{Cl})$ \\
\hline \multirow[t]{4}{*}{ I. All\# } & & $(n=244)$ & $(n=228)$ & \\
\hline & GG & I74 (7I) & i $72(76)$ & $1.29(0.49-3.37)$ \\
\hline & $A G$ & $62(26)$ & $46(20)$ & $1.80(0.66-4.97)$ \\
\hline & $A A$ & $8(3)$ & $10(4)$ & 1 \\
\hline \multirow[t]{4}{*}{ 2. Mixed race } & & $(n=83)$ & $(n=59)$ & \\
\hline & GG & 64 (77) & $45(76)$ & $2.93(0.51-16.72)$ \\
\hline & $A G$ & $17(21)$ & $10(17)$ & $3.78(0.58-24.75)$ \\
\hline & $A A$ & $2(2)$ & $4(7)$ & $\mathrm{I}$ \\
\hline \multirow[t]{4}{*}{ 3. Black } & & $(n=161)$ & $(n=169)$ & \\
\hline & GG & $110(68)$ & $127(72)$ & $0.87(0.27-2.76)$ \\
\hline & $A G$ & $45(28)$ & $36(24)$ & $1.25(0.37-4.21)$ \\
\hline & $A A$ & $6(4)$ & $6(4)$ & I \\
\hline
\end{tabular}

\#All $(I)=$ Mixed race (2) and Black (3) population groups combined

$\mathrm{OR}^{\prime}$ = crude odds ratio adjusted for ethnic group in the combined ethnic group analysis

trols were analysed for the -308 polymorphisms in the promoter region of TNF- $\alpha$.

\section{DNA extraction}

Genomic DNA was extracted from $200 \mu$ l of whole blood using the QiAamp Spin Blood Kit (QIAGEN, Valencia, $\mathrm{CA}$ ) in accordance with manufacturer's instructions.

\section{Cytokine genotyping}

The A and G alleles at position -308 in the promoter region of the TNF- $\alpha$ gene were identified using the amplification refractory mutation system polymerase chain reaction (ARMS-PCR) methodology as previously described [24]. A total of 2 ul (25-100 ng) of DNA was used in each ARMS-PCR reaction. The PCR primer sequences were as follows:

Generic primer (antisense): 5'-tctcggtttcttctccatcg-3'

Primer G, allele1 (sense): 5'-ataggttttgaggggcatgg-3'

Primer A, allele2 (sense): 5'-aataggttttgaggggcatga-3'

The amplified ARMS-PCR products (PCR product size = $184 \mathrm{bp}$ ) were identified by gel electrophoresis on $2 \%$ agarose gels stained with ethidium bromide.

\section{Statistical analysis}

Statistical analyses were performed using STATA version 8 . The allele frequency of the -308 TNF- $\alpha$ polymorphism was compared between the patients and control groups using the $X^{2}$ test. Unconditional logistic regression was used to estimate odds ratios (OR's) for developing cancer of the cervix in relation to the -308 TNF- $\alpha$ gene polymorphism. These OR's were adjusted for the following confounding factors; ethnic group, 5 year age group, years of education, age at first sexual intercourse, number of sexual partners, urban/rural living, number of Pap smears, injectable/oral contraceptive use, smoking, and parity.

\section{Results}

To evaluate the accuracy of the assigned TNF- $\alpha$ genotypes a total of twenty-five samples were randomly chosen and the results were confirmed by repeating the ARMS-PCR. Notably there were no discrepant results detected when the ARMS-PCR assay was repeated on the samples.

The genotype distribution of the polymorphism at position -308 of the TNF- $\alpha$ promoter region in the cases and controls among the two South African ethnic groups are shown in Table 1. There were no significant differences in the distribution of TNF- $\alpha$ allelic polymorphisms and the risk of developing cervical cancer in the mixed race group, (OR, 2.93; 95\% CI, 0.51-16.72) or the black group (OR, $0.87 ; 95 \% \mathrm{CI}, 0.27-2.76$ ). In addition, when the data was adjusted for potential confounding factors (adjusted for 5 year age group, education, age at first sex, number of sexual partners, number of Pap smears, injectable/oral contraceptive use, smoking, and parity), no significant association was observed (data not shown).

As there were no significant differences in the distribution of the -308 TNF- $\alpha$ alleles in the cervical cancer patients among the two South African ethnic populations, the data was combined to compare allele distributions to other population groups (Table 2). Interestingly, the genotype distribution of the -308 TNF-a genotypes for the South African cancer cases were different to those reported in a Korean population group (homozygous GG $71 \%$ vs $90 \%$; and heterozygous AG $26 \%$ vs $6 \%$ ). In addition, the distributions of the - 308 TNF- $\alpha$ alleles in the two South African control groups were combined to compare the genotype distribution to other population groups (Table 3 ). The genotype distribution for the homozygous GG and AA - 
Table 2: Distribution (\%) of -308 TNF- $\alpha$ genotypes in women with cervical cancer among different population groups.

\begin{tabular}{|c|c|c|c|c|}
\hline Genotype & *South African n = 244 n (\%) & ${ }^{+}$Korea (South) n = 5 I n (\%) & tUSA $n=127 n(\%)$ & §Zimbabwe $n=103$ n (\%) \\
\hline GG & $174(7 \mid)$ & $46(90)$ & $91(72)$ & $74(72)$ \\
\hline AG & $62(26)$ & $3(6)$ & $27(21)$ & $28(27)$ \\
\hline AA & $8(3)$ & $2(4)$ & $9(7)$ & $I(1)$ \\
\hline
\end{tabular}

*Combined Black and mixed race cancer case groups in this study (There were no differences in the distribution of the -308 TNF- $\alpha$ alleles between the two South African ethnic populations, thus the data was combined to compare genotype distributions to other population groups).

Data reported by; ${ }^{+}[14] ;{ }^{\dagger}[9] ; \S[21]$.

308 genotypes for the combined South African data were similar to those reported in Zimbabwean [21], Chinese [25]; Italian [26] and Korean [14] populations. However, the distribution of the heterozygous AG genotype was notably different in the Chinese and Korean compared to the South African control group (8\% versus $20 \%$ ). In addition, there was an increased frequency of the -308 TNF- $\alpha$ A allele and decrease in the G allele in the British Caucasoid group [24] when compared to the South African population group.

\section{Discussion}

Although the Pap smear screening has reduced cervical cancer mortality in developed countries, 35000 women die from this disease every year in the United States and Europe [27]. The current treatments for cervical cancer are invasive, costly, limited, uncomfortable, inefficient and recurrence is a common outcome [28]. There are several prophylactic and therapeutic clinical HPV vaccine trials that are in progress $[29,30]$, which may assist in reducing this disease burden worldwide. However, while these strategies are commendable it is important to investigate other host or viral markers that contribute to the different stages of cervical disease and thus may provide an effective tool for the treatment of cervical cancer. It is accepted that persistent HRHPV-induced infection is the hallmark of cervical cancer.

Indeed, other co-factors such as viral load, lifestyle factors, high parity, smoking, long-term use of contraceptives and other sexually transmitted diseases have also been established as risk cofactors for cervical cancer among women with persistent HPV infections [31]. In addition, several studies have indicated that the polymorphisms in the pro- moter region of -308 TNF- $\alpha$ may be a contributing factor for the development of cervical cancer $[18,21,32]$. However, the results of these studies have been contradictory. Thus in the present study we sought to identify the possible link between -308 A/G TNF- $\alpha$ allele polymorphism and the progression of cervical cancer among two ethnic population groups in South Africa. We found no significant differences between the -308TNF- $\alpha$ allele polymorphism and cervical cancer risk among the two South African ethnic population groups. In addition we observed no significant differences in the distribution of the high (AA), medium (AG) or low (GG) genotypes of TNF- $\alpha$ among the South African cervical cancer patients and healthy controls (and in the combined race groups) $\left(X^{2}=2.26\right)$ even when the data were adjusted for potential confounders (data not shown).

The findings in our study are similar to those reported by Stanczuk et al., [21], who investigated the association of $308 \mathrm{TNF}-\alpha$ gene polymorphism with cervical cancer among a Zimbabwean population [21]. They found no significant differences in the distribution of the high, medium or low producing alleles in the cervical cancer patients and healthy women. However, their study was based on a small sample size and the authors suggested that a larger cohort should be investigated to challenge this association, as their lack of association using a small sample size may have affected the statistical power of the study. Although our study included a large sample size we were unable to confirm this possibility and found no correlation between -308 TNF- $\alpha$ polymorphism and the risk of developing cervical cancer among the South African population. Similar reports were documented by others $[9,22,33]$ and discordant with those previously reported

Table 3: Distribution (\%) of -308 TNF- $\alpha$ genotypes in the combined South African control population groups and other populations.

\begin{tabular}{|c|c|c|c|c|c|c|}
\hline Genotype & $\begin{array}{l}* \text { South African } \\
\mathbf{n}=\mathbf{2 2 8} \mathrm{n}(\%)\end{array}$ & $\begin{array}{l}\wedge \text { China (North) } \\
n=300 \mathrm{n}(\%)\end{array}$ & $\begin{array}{l}\text { \#Italy (North) } \\
n=216 \text { n (\%) }\end{array}$ & $\begin{array}{l}\text { 'Korea (South) } \\
\mathrm{n}=92 \mathrm{n}(\%)\end{array}$ & $\begin{array}{l}\text { tManchester } \\
n=106 n(\%)\end{array}$ & $\begin{array}{l}\S Z \text { Zimbabwe } \\
n=101 \text { n (\%) }\end{array}$ \\
\hline GG & 172 (78) & $274(91)$ & $172(80)$ & $85(92.4)$ & $65(61)$ & $81(80)$ \\
\hline AG & $46(20)$ & $24(8)$ & 41 (19) & $7(7.6)$ & $24(23)$ & $18(18)$ \\
\hline AA & $10(4)$ & $2(0.7)$ & $3(1)$ & 0 & $17(16)$ & $2(2)$ \\
\hline
\end{tabular}

*Combined Black and mixed race control groups in this study (There were no differences in the distribution of the -308 TNF- $\alpha$ alleles between the two South African ethnic populations, thus the data was combined to compare genotype distributions to other population groups).

Data reported by ${ }^{\wedge}[25] ; \#[26] ;{ }^{+}[14] ; \dagger[24] ; §[21]$. 
in a population group from the United Kingdom [15]. In their study the authors demonstrated that the polymorphism in -308TNF- $\alpha$ gene significantly increased the susceptibility to cervical intraepithelial neoplasia 1 (CIN 1). However, as it is well-documented that most CIN1 regress spontaneously [34] it would have been beneficial if the authors extended the follow up screening to 36 months and thus the positive association demonstrated by the authors should be regarded with caution. In addition, CIN1 includes very mild to mild dysplasia, which is characterized by $20-25 \%$ replacement of the epithelium with immature cells and generally requires no treatment [29]. Furthermore, although in the same study the recruited subjects were age matched the authors did not provide the ethnic background for the population studied [15]. Thus, it is difficult to conclusively confirm or refute the possible ethnic disparity that may have contributed to the association differences observed between our study population and theirs.

Several reports in cervical cancer survival studies have indicated that the higher mortality rate in black populations is explained primarily by the more advanced clinical stage at time of diagnosis $[35,36]$. It was found that the percentage of early diagnosis among blacks and Hispanics were significantly low for cervical and breast cancer compared to non-Hispanics whites. It was therefore suggested that screening programs should be managed differently for specific ethnic groups as there is a significant disparity in the outcome of disease between ethnic populations. [36]. Indeed, the high incidence of cervical cancer in certain population groups may be due to poor screening programs, a lack of stringent follow-up treatments and lower socioeconomic status in different population groups. In the present study, we compared our cervical cancer patient group with those from other populations (Table 2). Although there was a difference in the distribution of the GG and AG of TNF- $\alpha$ between our study and the Korean population, this result should be taken with caution as the sample size for the Korean population was very small. It would therefore be valuable if the samples size was increased to examine these relationships adequately. Nevertheless, $26 \%$ vs $6 \%$ is significant. Furthermore, we compared the distribution of our control study group to those of other populations to identifying whether the distribution of the TNF- $\alpha$ gene at position -308 is different in other healthy population groups (Table 3 ). The distribution of the AATNF- $\alpha$, GGTNF- $\alpha$ and AGTNF- $\alpha$ genotypes at position -308 in the present control study group were similar to those observed in a Zimbabwean and Italian population and differed from those found in a Caucasian group. In addition, the distribution of the AGTNF- $\alpha$ genotype in the South African population group differed from that found in a Chinese and Korean population. These data highlight the possible variability of cytokine gene frequencies in different population groups and hence influence the disease outcome.

\section{Conclusion}

It is important to identify host or viral genetic markers that may facilitate the risk of developing cervical cancer. In addition, these markers would be useful in providing effective treatments and preventative strategies against HPV-induced infections. However, in this study we found no association between -308 TNF- $\alpha$ gene polymorphism and the risk of developing cervical cancer. Furthermore, our data highlight the need for further studies to clarify the association of ethnic variation and cytokine polymorphism as other potential confounding factors may contribute to the risk of developing cancer of the cervix.

\section{Competing interests}

The author(s) declare that they have no competing interests.

\section{Authors' contributions}

VAG designed the study, carried out the study and drafted the manuscript. DC performed the statistical analysis for the study. MH participated in the design and coordination of the case control study. A-LW participated in the coordination of the study. All authors read and approved the final manuscript.

\section{Acknowledgements}

The United States National Cancer Institute supported the cancer casecontrol study (grant number I ROI C473985). We thank Shayne Loubsher for technical assistance. VAG was supported by FHS.

\section{References}

I. zur Hausen H: Papillomaviruses causing cancer: evasion from host-cell host in early events in carcinogenesis. J Natl Cancer Inst 2002, 92:690-698.

2. Moscicki AB, Shiboski S, Broering J, Powell K, Clayton L, Jay N, Darragh TM, Brescia R, Kanowitz S, Miller SB, Stone J, Hanson E, Palefsky $\mathrm{J}$ : The natural history of human papillomavirus infection as measured by repeated DNA testing in adolescent and young women. J Pediatr 1998, I 32:277-284.

3. Wu TC: Immunology of the human papillomavirus in relation to cancer. Curr Opin Immunol 1994, 6:746-754.

4. Kadish AS, Ho GY, Burk RD, Wang Y, Romney SL, Ledwidge R, Angeletti RH: Lymphoproliferative responses to human papillomavirus (HPV) type 16 proteins E6 and E7: outcome of HPV infection and associated neoplasia. I Natl Cancer Inst 1997, 89: $1285-1293$.

5. Clerici M, Merola M, Ferrario E, Trabattoni D, Villa MI, Stefanon B, Venzon DJ, Shearer GM, De Palo G, Clerici E: Cytokine production patterns in cervical intraepithelial neoplasia: An association with human papillomavirus infection. J Natl Cancer Inst 1997, 89:245-250.

6. Govan VA, Carrara HRO, Sachs JA, Hoffman M, Stanczuk GA, Williamson AL: Ethnic differences in allelic distribution of IFN-g in South African women but no link with cervical cancer. J of Carcinogenesis 2003, 2:3.

7. Wu MS, Huang SP, Chang YT, Shun CT, Chang MC, Lin MT, Wang $\mathrm{HP}$, Lin JT: Tumor necrosis factor-alpha and interleukin- 10 promoter polymorphisms in Epstein-Barr virus-associated gastric carcinoma. J Infect Dis 2002, 185:106-109.

8. Shibata N, Ohnuma T, Takahashi T, Baba H, Ishizuka T, Ohtsuka M, Ueki A, Nagao M, Arai H: Effect of IL-6 polymorphism on risk of 
Alzheimer disease: Genotype-phenotype association study in Japanese cases. Am J Med Genet 2002, I I 4:436-439.

9. Calhoun ES, McGovern RM, Janney CA, Cerhan JR, Iturria SJ, Smith DI, Gostout BS, Persing DH: Host genetic polymorphism analysis in cervical cancer. Clin Chem 2002, 48(8): $1218-24$.

10. Kroeger KM, Carville KS, Abraham LJ: The $\mathbf{- 3 0 8}$ tumor necrosis factor-alpha promoter polymorphism effects transcription. Mol Immunol 1997, 34(5):39I-9.

II. Carswell EA, Old LJ, Kassel RL, Green S, Fiore N, Williamson B: An endotoxin-induced serum factor that causes necrosis of tumors. Proc Natl Acad Sci 1975, 72(9):3666-70.

12. Shishodia S, Majumdar S, Banerjee S, Aggarwal BB: Ursolic acid inhibits nuclear factor $-\kappa B$ activation induced by carcinogenic agents through suppression of $I \kappa B \alpha$ kinase and p 65 phosporylation: Correlation with down-regulation of cyclooxygenase 2, matrix metalloproteinase 9, and cyclin D I. Cancer Res 2003, 63:4375-4383

13. Raabe T, Bukrinsky M, Currie RA: Relative contribution of transcription and translation to the induction of tumor necrosis factor-alpha by lipopolysaccharide. J Biol Chem 1998, 273(2):974-80.

14. Jang WH, Yang YI, Yea SS, Lee YJ, Chun JH, Kim HI, Kim MS, Paik KH: The -238 tumor necrosis factor-alpha promoter polymorphism is associated with decreased susceptibility to cancers. Cancer Lett 200I, 66(I):4I-6.

15. Kirkpatrick A, Bidwell J, van den Brule AJ, Meijer CJ, Pawade J, Glew $\mathrm{S}$ : TNF alpha polymorphism frequencies in HPV-associated cervical dysplasia. Gynecol Oncol 2004, 92(2):675-9.

16. Lee JY, Kim HY, Kim KH, Kim SM, Jang MK, Park JY, Kim JH, Yoo JY: Association of polymorphism of IL- 10 and TNF- $\alpha$ genes with gastric cancer in Korea. Cancer Lett 2005, 225(2):207-2I 4.

17. Azmy IA, Balasubramanian SP, Wilson AG, Stephenson TJ, Cox A, Brown NJ, Reed MW: Role of tumour necrosis factor gene polymorphisms (-308 and -238) in breast cancer susceptibility and severity. Breast Cancer Res 2004, 6(4):R395-400.

18. Deshpande A, Nolan JP, White PS, Valdez YE, Hunt WC, Peyton CL, Wheeler CM: TNF-a promoter polymorphisms and susceptibility to human papillomavirus 16-associated cervical cancer. IID 2005, 191:969-976.

19. Tjiong MY, van der Vange N, ter Schegget JS, Burger MPM, ten Kate FW], Out TA: Cytokines in cervicovaginal washing fluid from patients with cervical neoplasia. Cytokine 200I, 14:357-360.

20. Chen G, Wilson R, Wang SH, Zheng HZ, Walker JJ, McKillop JH: Tumor necrosis factor alpha (TNF- $\alpha$ ) gene polymorphism and expression in pre-eclampsia. Clin Exp Immunol 1996, 104:154-I59.

21. Stanczuk GA, Sibanda EN, Tswana SA, Bergstrom S: Polymorphism at the -308-promoter position of the tumor necrosis factoralpha (TNF-alpha) gene and cervical cancer. Int J Gynecol Cancer 2003, 13:148-53.

22. Ghaderi M, Nikitina L, Peacock CS, Hjelmstrom P, Hallmans G, Wiklund F, Lenner P, Blackwell JM, Dillner J, Sanjeevi CB: Tumor necrosis factor a-II and DRI5-DQ6 (B*0602) haplotype increase the risk for cervical intraepithelial neoplasia in human papillomavirus 16 seropositive women in Northern Sweden. Epidemiol Biomarkers Prev 2001, 9:1067-1070.

23. Hoffman M, Cooper D, Carrara HRO, Rosenberg L, Kelly J, Stander I, Williamson A-L, De toit G, Shapiro S: Limited Pap screening associated with reduced risk of cervical cancer in South Africa. Int J Epidemiol 2003, 32:573-577.

24. Perrey C, Turner SJ, Pravica V, Howell WM, Hutchinson IV: ARMSPCR methodologies to determine IL-I0, TNK-alpha and TGF-beta-I gene polymorphism. Transplant Immunol 1999, 7:127-128.

25. Lu W, Pan K, Zhang L, Lin D, Miao X, You W: Genetic polymorphisms of interleukin (IL)-IB, IL-IRN, IL-8, IL-I 0 and tumor necrosis factor alpha\} and risk of gastric cancer in a Chinese population. Carcinogenesis 2005, 26(3):63I-6.

26. Perri F, Piepoli A, Bonvicini C, Gentile A, Quitadamo M, Di Candia M, Cotugno R, Cattaneo F, Zagari MR, Ricciardiello L, Gennarelli M, Bazzoli F, Ranzani GN, Andriulli A: Cytokine gene polymorphisms in gastric cancer patients from two Italian areas at high and low cancer prevalence. Cytokine 2005, 30(5):293-302.

27. Ferlay J, Bray F, Pisani P: GLOBOCAN 2002: cancer incidence, motality and prevalence worldwide. IARC Press 2004
28. Robinson W 3rd: Management of cervical cancer neoplasia. Cancer Treat Res 200I, 104:287-302.

29. Brinkman JA, Caffrey AS, Muderspach I, Roman LD, Kast WM: The impact of anti HPV vaccination on cervical cancer incidence and HPV induced cervical cancer lesions: Consequences for clinical management. Eur J Oncol 2005, 26: |29-|42.

30. Govan VA: Strategies for Human Papillomavirus therapeutic vaccines and other therapies based on the E6 and E7 oncogenes. Annals NYA Sci 2005 in press.

31. Wacholder S: Chapter 18: Statistical Issues in the design and analysis of studies of human papillomavirus and cervical neoplasia. I Nat Cancer Inst Monogr 2003, 3 I: I 25-30.

32. Azar KK, Tani M, Yasuda H, Sakai A, Inoue M, Sasagawa T: Increased secretion patterns of interleukin- 10 and tumor necrosis factor-alpha in cervical squamous intraepithelial lesions. Hum Pathol 2004, 35(I I): 1376-84.

33. Galloway DA: Papillomavirus vaccines in clinical trials. Lancet Infect Dis 2003, 8:469-75.

34. Gostout BS, Poland GA, Calhoun ES, Sohni YR, Giuntoli RL 2nd, McGovern RM, Sloan JA, Cha SS, Persing DH: TAPI, TAP2, and HLA-DR2 alleles are predictors of cervical cancer risk. Gynecol Oncol 2003, 3:326-32.

35. Shelton D, Paturzo D, Flannery J, Gregorio D: Race, stage of disease, and survival with cervical cancer. Ethn Dis 1992, 2:47-54.

36. Chen F, Trapido EJ, Davis K: Differences in stage at presentation of breast and gynecological cancers among whites, blacks, and Hispanics. Cancer 1994, 73:2838-2842.

\section{Pre-publication history}

The pre-publication history for this paper can be accessed here:

\section{http://www.biomedcentral.com/1471-2407/6/24/prepub}

Publish with Biomed Central and every scientist can read your work free of charge

"BioMed Central will be the most significant development for disseminating the results of biomedical research in our lifetime. "

Sir Paul Nurse, Cancer Research UK

Your research papers will be:

- available free of charge to the entire biomedical community

- peer reviewed and published immediately upon acceptance

- cited in PubMed and archived on PubMed Central

- yours - you keep the copyright
BioMedcentral 